\title{
Structural coloration of chitosan coated cellulose fabrics by electrostatic self-assembled poly (styrene-methyl methacrylate-acrylic acid) photonic crystals
}

\author{
Gönül Yavuz ${ }^{\mathrm{a}, 1}$, Andrea Zille ${ }^{\mathrm{b}, *, 1}$, Necdet Seventekin ${ }^{\mathrm{c}}$, Antonio P. Souto ${ }^{\mathrm{b}}$ \\ ${ }^{a}$ Textile and Apparel Research \& Application Center, Ege University, 35100, Izmir, Turkey \\ b 2C2T - Centro de Ciência e Tecnologia Têxtil, Universidade do Minho, Campus de Azurém, 4800-058, Guimarães, Portugal \\ ${ }^{\mathrm{c}}$ Ege University, Faculty of Engineering, Textile Engineering Department, 35100, Izmir, Turkey
}

\section{A R T I C L E I N F O}

\section{Keywords:}

Photonic crystal

Chitosan

Textile

Cotton

Structural color

Iridescence

\begin{abstract}
A B S T R A C T
The structural coloration of a chitosan-coated woven cotton fabric obtained by glutaraldehyde-stabilized deposition of electrostatic self-assembled monodisperse and spherically uniform $(250 \mathrm{~nm})$ poly (styrene-methyl methacrylate-acrylic acid) photonic crystal nanospheres (P(St-MMA-AA)) was investigated. Bright iridescent coatings displaying different colors in function of the viewing angle were obtained. The SEM, diffuse reflectance spectroscopy, TGA, DSC and FTIR analyses confirm the presence of structural color and the glutaraldehyde and chitosan ability to provide durable chemical bonding between cotton fabric and photonic crystal (PCs) coating with the highest degradation temperature and the lowest enthalpy. The coatings are characterized by a mixture of face-centered cubic and hexagonal close-packed arrays alternating random packing regions. For the first time a cost-efficient structural coloration with high washing and light fastness using self-assembled P(St-MMA-AA) photonic crystals was successfully developed onto woven cotton fabric using chitosan and/or glutaraldehyde as stabilizing agent opening new strategies for the development of dye-free coloration of textiles.
\end{abstract}

\section{Introduction}

Colors can be produced by different methods like emission, interference, scattering or optical absorption. A pigment mainly relies on the selective absorption of light by chemical chromophores to achieve coloration (Zhao, Xie, Gu, Zhu, \& Gu, 2012). Differently, structural colors are originating from micro structural variation at a length scale comparable to the optical wavelength (Saito, 2016). Structural colors are responsible for the most vivid and brightest colors in nature. Numerous examples of structural coloration can be found in insects, birds, mollusks, sea mice, fish, plants and mineral gems (Liu, Shao et al., 2015). They are mainly used by animals and plants for signaling, mimicry and mate (Vignolini et al., 2012). Research currently focus in studying structural color properties in the wavelength ranges of ultraviolet (UV) light, visible light, and infrared (IR) light) using both inorganic and organic materials (Diao \& Liu, 2012). Structural colors have a multiplicity of potential applications due to their high-resistance to discoloration and inimitability. Moreover, structural colors are a green technology due to the lack of chemical pigments, high efficiency in energy consumption and in the use of light (Saito, 2016; Zhao et al., 2012). Most of the structural colors found in nature are originated from five fundamental optical processes and their combinations: thin-film interference, multilayer interference, diffraction grating effect, photonic crystals, and light scattering (Kinoshita \& Yoshioka, 2005). Photonic crystals (PCs) are highly ordered materials that possess a periodically modulated dielectric constant, having the properties of confining and controlling the propagation of light due to the existence of photonic band gap, a band of frequencies where light propagation in the photonic crystal is forbidden (Liu, Shao et al., 2015). They can manipulate pathways of certain light waves with periodic array structures allowing structural color formation. This unique phenomenon is attributed to the light inside the array interacting with the crystal structures (Liau \& Huang, 2008). PCs are important for applications in paints, paper, cosmetics, modulators, sensors, filters, laser and light emitting diodes (LEDs) (Jones, Burdett, Ryan, \& Walsh, 2016; Sun \& Williams, 2012). The most simplest configuration of PCs are monodisperse highly charged micro or nanoparticles colloidal that spontaneously self-assemble into face-centered cubic or body-centered cubic

\footnotetext{
* Corresponding author at: 2C2T - Centro de Ciência e Tecnologia Têxtil, Departamento de Engenharia Têxtil, Universidade do Minho, Campus de Azurém, 4800 - 058 Guimarães, Portugal.

E-mail address: azille@2c2t.uminho.pt (A. Zille).

${ }^{1}$ These authors contributed equally to this work.
} 
crystalline colloidal arrays in low ionic strength aqueous solutions $\mathrm{Xu}$, Friedman, Humfeld, Majetich, \& Asher, 2002). Colloidal particles are of particular interest because of their photonic band gaps and strong interaction with light and have long been used as the major components of industrial products (Zhao, Shang, Cheng, \& Gu, 2014). The properties of these monodispersed colloidal spheres can be closely controlled by varying different parameters such as diameter, crystallinity, functional group, bulk substructure, chemical composition, interfacial free energy and surface charge density (Xia, Gates, Yin, \& Lu, 2000). Moreover, colloidal photonic structures can be easily fabricated using different methods such as auto-cloning process (Turberfield, Campbell, Sharp, Harrison, \& Denning, 2000), holographic lithography (Kuramochi et al., 2002), colloidal and block-copolymer self-assembly (Kang, Walish, Gorishnyy, \& Thomas, 2007; Kim, Lim, Lee, Heo, \& Yang, 2010). Colloidal self-assembly is the most reliable method due to the low production costs of PCs over large areas, and the wide range of shapes that can be obtained (Galisteo-López et al., 2011). Electrostatic self-assembly is based on the alternating adsorption of multiply charged cationic and anionic species and it becomes one of the most promising methods for thin-film fabrication (Uğur \& Sarışık, 2011). Its simplicity and high coating quality combined with the achievable uniform distribution of nanoparticles in wide areas opens broad perspectives for this technique both in textile research and in industry (Ostrander, Mamedov, \& Kotov, 2001). Conventional dyeing and printing processes in textile industry face many challenges such as the use of huge amounts of water and chemicals as well as wastewater generation and low color fastness. Structural coloration applications can provide enhanced properties to textile coloration industry since they have special ability and features that differ from pigments and dyes. Their colors have a physical and not chemical origin and are brighter, more deeply saturated, free from photobleaching, and longer lasting (Diao, Liu, Toh, Shi, \& Zi, 2013; Zhao et al., 2012). Many researchers are working on photonics crystals in the last decade, however most of the research is focused on electronics in smooth glass and silica surfaces. Little literature exists about artificial photonic materials for structural color applied to textile substrates due to the lack of an efficient generation of 3D nano-architectures technologies (Lee, Shim, Hwang, Yang, \& Kim, 2013; Liu et al., 2015a). There are many challenges for producing structural color on a textile surface because of its irregular surface morphologies and structural gaps. For practical applications, a convenient method of fabricating a uniform film over a large textile area with optimized washing fastness and fabric feeling is required (Liu, Shao et al., 2015).

The main objective of this study was to develop a stable structural color onto woven cotton fabrics for textile applications starting from the preliminary results obtained and recently published as conference proceeding (Yavuz, Zille, Seventekin, \& Souto, 2017). Colloidal photonic crystals based on monodisperse nanospheres of poly (styrenemethyl methacrylate-acrylic acid) were synthesized by soap-free emulsion polymerization and deposited by electrostatic self-assembly technique onto a chitosan-cationized woven cotton fabric. A second chitosan layer on the top of the PCs as protective and color modulating coating was also applied. Chitosan is a cationic polysaccharide derived from chitin with a number of unique properties (Hubbe, Rojas, \& Lucia, 2015). It was chosen for this work because of its positive charge that allows the formation of strong film on the surface of both chemical and natural fibers (Osman, Michael, \& Gohar, 2010; Vakhitova \& Safonov, 2003). Moreover, chitin in nature is the scaffold of numerous photonic structures (Choi, Xie, \& Xia, 2009; Yang et al., 2013). Coated fabrics were evaluated for coating efficiency and resistance, chemical properties and color variation by optical and Scanning electron microscopy (SEM), thermogravimetric analysis (TGA), Dynamic calorimetric analysis (DSC), Attenuated total reflectance Fourier transform infrared spectroscopy (ATR-FTIR), diffuse reflectance spectroscopy, light and washing fastness. To the authors knowledge, this is the first time that structural coloration using self-assembled poly (styrene-methyl methacrylate-acrylic acid) photonic crystals is successfully developed onto woven cotton fabric using chitosan and/or glutaraldehyde as stabilizing agent.

\section{Materials and methods}

\subsection{Materials}

Commercial black dyed cotton fabric with a warp density of 34 threads $\mathrm{cm}^{-1}$, a weft density of 30 threads $\mathrm{cm}^{-1}$ and weight per unit area of $140 \mathrm{~g} \mathrm{~m}^{-2}$ was used in this study. The samples were pre-washed with a $1 \mathrm{~g} \mathrm{~L}^{-1}$ of non-ionic detergent solution at $30^{\circ} \mathrm{C}$ for $30 \mathrm{~min}$ and then rinsed with water for another $15 \mathrm{~min}$ in order to minimize contaminations. Chitosan (DD 85\%, ChitoClear hq95-43000, $\mathrm{Mw}=350 \mathrm{kDa}$ ) was purchased from Primex (Iceland). Styrene (St), methyl methacrylate (MMA), and acrylic acid (AA) were distilled before use. All the other reagents were analytical grade purchased from Sigma-Aldrich, St. Louis, MO, USA and used without further purification.

\subsection{Preparation of monodispersed $P(S t-M M A-A A)$ nanospheres}

Monodispersed latex spheres of poly (styrene-methyl methacrylateacrylic acid) (P(St-MMA-AA)) were synthesized by a modified soap-free emulsion polymerization method in a three-necked flask equipped with a reflux condenser and a mechanical stirrer as previously described by Cong and Cao (2003). Briefly, the monodispersed P(St-MMA-AA) colloidal particles were synthesized as follows: $120 \mathrm{~mL}$ of aqueous solution (A), containing $0.4 \mathrm{~g}$ of $\mathrm{Na}_{2} \mathrm{~S}_{2} \mathrm{O}_{8}$ and $0.8 \mathrm{~g}$ of $\mathrm{NaHCO}_{3}$ in a funnel, and $25 \mathrm{~mL}$ of monomer mixture (B), consisting of St/MMA/AA (90:5:5 v/v/ $\mathrm{v})$ in another funnel, were added at the same time into a $250 \mathrm{~mL}$ threenecked flask. The mixture was stirred at $70{ }^{\circ} \mathrm{C}$ in $\mathrm{N}_{2}$ atmosphere for $5 \mathrm{~h}$ to obtain a homogeneous dispersion of particles with uniform size distribution.

\subsection{Cationization process}

Cationic cotton fabrics $(7 \times 7 \mathrm{~cm})$ were prepared by padding chitosan $(\mathrm{CH})$ solutions of 1.0, 0.5 and $0.3 \mathrm{wt} \%$ dissolved in $1 \%$ acetic acid aqueous solution. The $\mathrm{CH}$ solutions were stirred at $300 \mathrm{rpm}$ for $30 \mathrm{~min}$ at $70^{\circ} \mathrm{C}$. The heating was kept until the chitosan was completely dissolved. The mixture was stirred until room temperature was reached. The samples were padded in a mini-foulard through the $\mathrm{CH}$ solution at $1.5 \mathrm{bar}$ of pressure and $4 \mathrm{rpm}$ ( $80 \%$ pick-up). The excess coating was then removed by gently rinsing with distilled water and the samples dried in an oven for $12 \mathrm{~h}$ at $50^{\circ} \mathrm{C}$. Cationic cotton fabrics $(7 \times 7 \mathrm{~cm})$ used for all the subsequent experiments were prepared only with a chitosan $(\mathrm{CH})$ solutions of $1.0 \mathrm{wt} \%$.

\subsection{Coating of cotton fabrics with photonic crystals}

Three types of samples were tested: (1) Pristine cotton sample dipped in a $14 \%$ photonic colloid solution for $5 \mathrm{~min}$ and then dried at $60{ }^{\circ} \mathrm{C}$; (2) Cationized cotton sample treated as sample 1; (3) Sample 2 followed by a second impregnation in a crosslinked chitosan solution and dried at $60^{\circ} \mathrm{C}$. Crosslinked chitosan solution was prepared by dissolving $1 \mathrm{~g}$ of chitosan in $100 \mathrm{~mL}$ of $1 \%(\mathrm{v} / \mathrm{v})$ aqueous acetic acid mixed with $50 \mathrm{~mL}$ of $1 \%(\mathrm{~m} / \mathrm{m})$ glutaraldehyde solution for $30 \mathrm{~min}$.

\subsection{Scanning electron microscopy (SEM) and energy dispersive X-ray spectroscopy (EDS)}

Morphology analyses of the coatings were carried out with an UltraHigh Resolution Field Emission Gun SEM, NOVA 200 Nano SEM, FEI Company. Secondary electron images were acquired with an acceleration voltage of $5 \mathrm{kV}$, while backscattering electron images were 
obtained with an acceleration voltage of $15 \mathrm{kV}$. To improve conductivity, the tested surfaces were covered with a film of Au-Pd (80-20 wt\%) using a high-resolution sputter coater, 208HR Cressington Company, coupled to a MTM-20 Cressington high resolution thickness controller.

\subsection{Fourier transform infrared spectroscopy (FTIR)}

A Shimadzu FTIR spectrophotometer (IR-Affinity 1) with an attenuated total reflectance accessory (ATR) was used to record the FTIR spectra of the fabric samples. Spectra were collected in the region of $4000-400 \mathrm{~cm}^{-1}$ and at a resolution of $4 \mathrm{~cm}^{-1}$ with 45 scans at room temperature. A background scan with no samples and no pressure was acquired before the spectra collection.

\subsection{Photographs}

Optical photos of the fabrics coated with PCs were taken with a Nikon CoolPix4300 digital camera. The pictures were acquired under natural light, at the same time and environmental conditions, perpendicularly to the fabrics and at the distance of $15 \mathrm{~cm}$. In the case of the multi-angle photographs the camera was disposed at different angles $\left(0^{\circ}, 45^{\circ}\right.$ and $\left.90^{\circ}\right)$ using a goniometer maintaining the same distance and using the same sample.

\subsection{Thermogravimetric analysis (TGA)}

TGA was carried on a Pyris 1 TGA (Perkin Elmer, USA) according to the standard ISO 11358:1997(E). The TGA trace was obtained in the range $40-700^{\circ} \mathrm{C}$ under nitrogen atmosphere with a flow rate of $20 \mathrm{~mL} /$ min and heating rate of $10^{\circ} \mathrm{C} / \mathrm{min}$. Samples were dried at $60^{\circ} \mathrm{C}$ for $1 \mathrm{~h}$ and placed into a porcelain sample pan before analysis. Graph was plotted with weight (percentage) vs. temperature.

\subsection{Differential scanning calorimeter (DSC) analysis}

DSC was carried on a Power compensation Diamond DSC (Perkin Elmer, USA) with an Intracooler ILP, based on the standards ISO 113571:1997, ISO 11357-2:1999 and ISO 11357-3:1999. Samples were dried at $60^{\circ} \mathrm{C}$ for $1 \mathrm{~h}$ and placed in an aluminum sample pan before testing. The analysis was carried out in nitrogen atmosphere with a flow rate of $20 \mathrm{~mL} / \mathrm{min}$ and heating rate of $10{ }^{\circ} \mathrm{C} / \mathrm{min}$. The thermogram was obtained in the range of $30^{\circ} \mathrm{C}-500^{\circ} \mathrm{C}$. Graph was plotted with heat flow vs. temperature.

\subsection{Diffuse reflectance spectroscopy}

The color of the fabrics was evaluated using a Spectraflash 600 (Datacolor) diffuse reflectance spectrophotometer at standard illuminant D65 (LAV/Spec. Incl., d/8, D65/10 ${ }^{\circ}$ ). Five areas on each sample were measured in various positions, and the results represent average values with up to $1 \%$ variation. All measurements were performed in triplicate. The responses analyzed were the color characteristics: K/S, $L^{*}, a^{*}, b^{*} . K / S$ is the color strength calculated using Kubelka-Munk's equation (K/S = (1-R) $2 / 2 R$, where $R$ is the reflectance). $L^{*}$, $a^{*}$, and $b^{*}$ are the coordinates of the color in the cylindrical color space, based on the theory that color is perceived by black-white ( $\mathrm{L}^{*}$, lightness), redgreen $\left(\mathrm{a}^{*}\right)$, and yellow-blue $\left(\mathrm{b}^{*}\right)$ sensations. The lightness, $\mathrm{L}^{*}$, represents the darkest black at $\mathrm{L}^{*}=0$ and the brightest white at $\mathrm{L}^{*}=100$. The color channels, $\mathrm{a}^{*}$ and $\mathrm{b}^{*}$, will represent true neutral gray values at $a^{*}=0$ and $b^{*}=0$. The red/green opponent colors are represented along the $a^{*}$ axis, with green at negative $a^{*}$ values and red at positive $a^{*}$ values. The yellow/blue opponent colors are represented along the $b *$ axis, with blue at negative $b^{*}$ values and yellow at positive $b$ * values. The results were also summarized by the overall color difference $\left(\Delta \mathrm{E}^{*}\right)$ value using the black dyed cotton as control.

\subsection{Light fastness tests}

The light fastness was applied in an Atlas XenoTest $150 \mathrm{~S}$ chamber with a filtered Xenon lamp with an intensity of $60 \mathrm{Wm}-2$ according to ISO 4892-2 Method A without water spraying. The light of the Xenon lamp was filtered under $\lambda>300 \mathrm{~nm}$ with an UV window combined with six IR filter glasses. The XenoTest creates an accelerated environment of the natural weathering conditions, simulating materials behavior during its lifetime.

\subsection{Washing fastness}

The washing fastness was evaluated according to the standard ISO $105 \mathrm{C} 06, \mathrm{~A} 1 \mathrm{~S}$ method at a temperature of $40{ }^{\circ} \mathrm{C}$.

\section{Results and discussion}

In order to determine the most effective chitosan concentration for cotton cationization, three different chitosan solutions $(1.0 \%, 0.5 \%$, $0.3 \%$ ) were padded onto the dyed cotton before the nanophotonic crystals addition by dipping method. The binding efficiency was monitored monitoring the change in color coordinates (Table 1) according to CIELAB system, where $\mathrm{L}^{*}$ characterizes the lightness of a color and can range between 0 (dark) and 100 (light); a* defines a color on a redgreen axis; and $b^{*}$ describes the blue part of the color (Okubo, Kanawati, Richards, \& Childress, 1998). The color difference $\left(\Delta E^{*}\right)$ and color coordinate values of the fabrics coated with the nanophotonic crystals are directly proportional to the change in chitosan concentration. Higher is the amount of chitosan, higher are $\Delta E^{*}$ and color coordinates values. A chitosan concentration higher than $0.5 \%$ does not shown significant improvements in color differences. However, the study was conducted at the higher concentration of $1 \mathrm{wt} \%$ due to the even coating and highest cationization effect obtained.

Termogravimetry (TGA) analysis provides information about fiber degradation indicating the temperature at which mass loss starts and also gives unique features at the molecular level of the analyzed material. TGA showed that the degradation of untreated and chitosan treated cotton fabric takes place in two well-differentiated steps (Fig. 1). In the first step the polymer showed a small initial weight loss between 35 and $100{ }^{\circ} \mathrm{C}$. This first mass loss is associated with the removal of physically absorbed water and pore liquor that were not removed during the drying process (Kumar, Joo, Choi, Koo, \& Chang, 2004). Above this temperature the weight remains constant until a second phase attributed to $\alpha$-cellulose decomposition that starts at around $290{ }^{\circ} \mathrm{C}$ and continues till $376{ }^{\circ} \mathrm{C}$ with a major weight loss of about 70\% (Luduena, Fasce, Alvarez, \& Stefani, 2011). The highest loss occurs at the maximum decomposition temperature $\left(\mathrm{T}_{\max }\right)$ of $334^{\circ} \mathrm{C}$ as shown in derivative thermal gravimetric (DTG) peak (Table 2). Slowly, a progressive carbonized structure was formed as the temperature increased further. The high solid residue content $(18 \%)$ at $700{ }^{\circ} \mathrm{C}$ might be due to the presence of impurities such as cations $\left(\mathrm{Na}^{+}, \mathrm{K}^{+}, \mathrm{Ca}^{2+}\right.$ ), which acted like a bridge between cellulose polymer chains, or due to a

\section{Table 1}

Color strength $(\mathrm{K} / \mathrm{S})$, overall color difference $\left(\Delta E^{*}\right)$ and shift of the coordinates of the color in the cylindrical color space: lightness $\left(L^{*}\right)$, red-green $\left(a^{*}\right)$, and yellow-blue $\left(b^{*}\right)$ of the fabrics with different chitosan concentrations. Black dyed cotton $\mathrm{K} / \mathrm{S}=697.93(\mathrm{n}=3$; S.D. $<1 \%)$.

\begin{tabular}{llllll}
\hline Sample $^{\mathrm{a}}$ & $\mathrm{K} / \mathrm{S}$ & $\Delta \mathrm{E}^{*}$ & $\mathrm{~L}^{*}$ & $\mathrm{a}^{*}$ & $\mathrm{~b}^{*}$ \\
\hline $\mathrm{CO}+\mathrm{CH}$ & 584.5 & 30.3 & 0.3 & 0.4 & 3.3 \\
$\mathrm{CO}+\mathrm{CH}(0.3 \%)+\mathrm{pH}$ & 214.31 & 14.4 & 13.8 & 1.5 & 3.6 \\
$\mathrm{CO}+\mathrm{CH}(0.5 \%)+\mathrm{pH}$ & 141.85 & 20.5 & 20.1 & 1.2 & 3.6 \\
$\mathrm{CO}+\mathrm{CH}(1.0 \%)+\mathrm{pH}$ & 132.78 & 22.2 & 21.7 & 1.5 & 4.8 \\
\hline
\end{tabular}

${ }^{a}$ CO: Black dyed cotton; $\mathrm{CH}: 0.3,0.5$ or $1 \%$ Chitosan solution; $\mathrm{pH}: 14 \%$ Photonic colloid. 


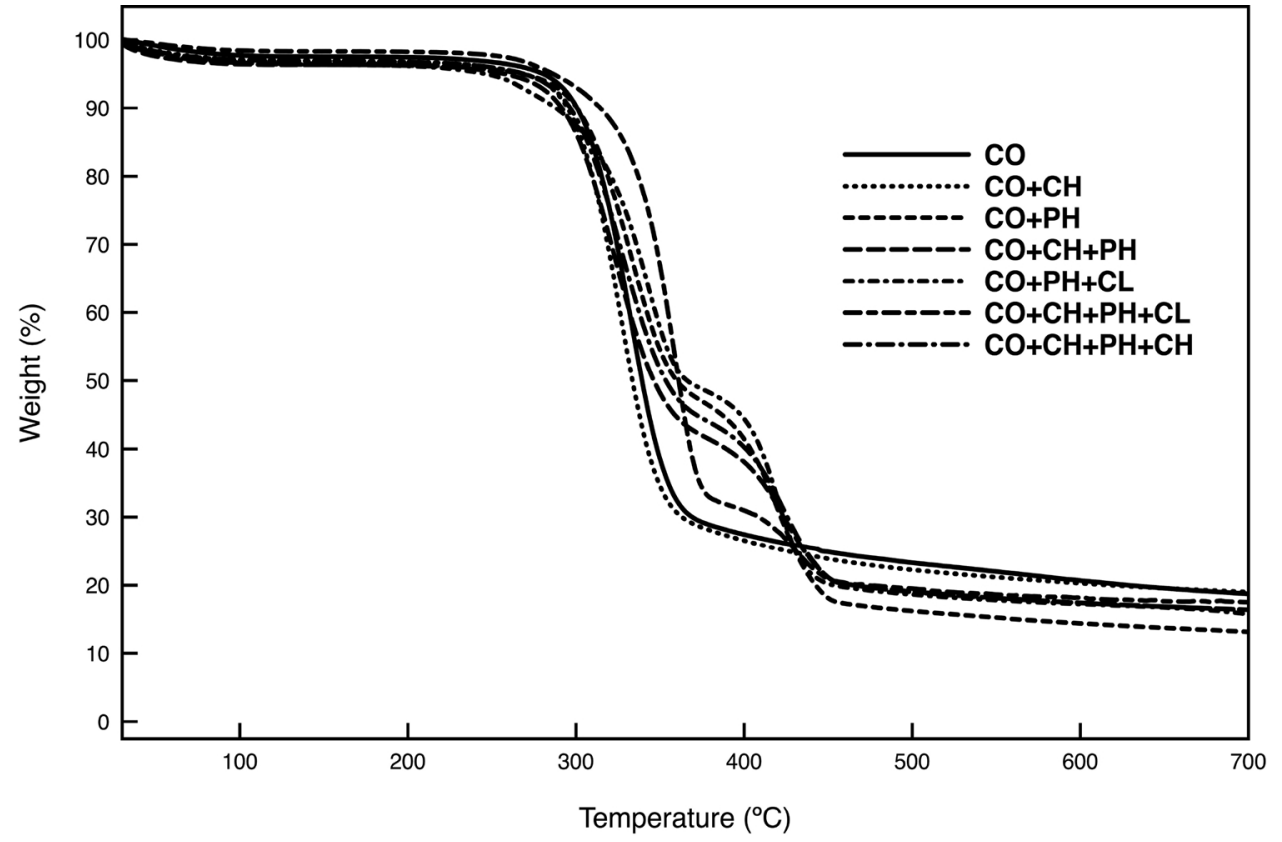

Fig. 1. Thermogravimetric (TGA) curve of the cotton fabrics with different coating procedures from $20^{\circ} \mathrm{C}$ to $700{ }^{\circ} \mathrm{C}$ performed at a heating rate of $10^{\circ} \mathrm{C} / \mathrm{min}$ under nitrogen atmosphere with a flow rate of $20 \mathrm{~mL} / \mathrm{min}$. CO: Black dyed cotton; $\mathrm{CH}: 1 \%$ Chitosan solution; $\mathrm{pH}$ : 14\% Photonic colloid; CL: 1\% cross-linked chitosan solution.
Table 2

Main DSC thermal transitions, TGA weight loss temperature peaks and residual weight of samples. $(n=3$; S.D. $<1 \%)$.

\begin{tabular}{lllll}
\hline Sample $^{\mathrm{a}}$ & $\mathrm{Tm}\left({ }^{\circ} \mathrm{C}\right)$ & $\Delta{\mathrm{H}\left(\mathrm{Jg}^{-1}\right)}^{\mathrm{T} \text { peaks of } 1 \mathrm{st}}$ & $\begin{array}{l}\text { Residual } \\
\text { derivative }\left({ }^{\circ} \mathrm{C}\right)\end{array}$ & $\begin{array}{l}\text { weight at } \\
700{ }^{\circ} \mathrm{C}(\%)\end{array}$ \\
\hline $\mathrm{CO}$ & & & & 18.1 \\
$\mathrm{CO}+\mathrm{CH}$ & 307.1 & 148.2 & 333.9 & 19.0 \\
$\mathrm{CO}+\mathrm{pH}$ & 312.5 & 123.5 & 326.4 & 13.2 \\
& $308.8 ;$ & $72.0 ; 97.5$ & $333.0 ; 420.2$ & \\
$\mathrm{CO}+\mathrm{CH}+\mathrm{pH}$ & 426.9 & & & \\
& $300.8 ;$ & $31.9 ; 126.8$ & $323.4 ; 423.8$ & 16.4 \\
$\mathrm{CO}+\mathrm{pH}+\mathrm{CL}$ & 428.2 & & & 15.8 \\
& $309.3 ;$ & $67.6 ; 96.0$ & $343.0 ; 420.4$ & 17.5 \\
$\mathrm{CO}+\mathrm{CH}+\mathrm{pH}$ & 427.7 & & & \\
$\quad 351.1 ;$ & $30.5 ; 77.8$ & $360.5 ; 430.5$ & \\
$\quad+\mathrm{CL}$ & 434.6 & & & \\
$\mathrm{CO}+\mathrm{CH}+\mathrm{pH}$ & $305.1 ;$ & $80.8 ; 59.9$ & $327.1 ; 423.9$ & 16.4 \\
$\quad+\mathrm{CH}$ & 432.6 & & & \\
\hline
\end{tabular}

${ }^{\text {a }} \mathrm{CO}$ : Black dyed cotton; $\mathrm{CH}: 1 \%$ Chitosan solution; $\mathrm{pH}: 14 \%$ Photonic colloid; CL: $1 \%$ cross-linked chitosan solution.

low carbonization degree (Pooja \& Chandra, 2009). No noticeable degradation peaks for chitosan are visible in the $T_{g}$ spectra of cotton fabric. The introduction of the photonic crystals in the coating show a third mass drop with a DTG peak around $420^{\circ} \mathrm{C}$. This peak is attributed to the decomposition temperature of the (P(St-MMA-AA)) nanospheres. The unusual high decomposition temperature for this type of material may be caused by hydrogen bonds among nanospheres and cellulose matrix (Zhu, Zhang, Wang, \& Chen, 2017). No significant variations can be noted among the different configuration of photonic crystals with or without chitosan coating. However, the samples that were submitted to crosslinking treatment by glutaraldehyde showed higher degradation temperature for both cellulose and (P(St-MMA-AA)) peaks (DTG peaks at $360^{\circ} \mathrm{C}$ and $430{ }^{\circ} \mathrm{C}$, respectively). The chemical crosslinking method by glutaraldehyde was applied to induce durable chemical bonding and higher washing durability between cotton fabric chitosan and photonic crystals (Mocanu, Nichifor, Mihai, \& Oproiu, 2013).

The differential scanning calorimetry (DSC) allows rapid detection and measurement of the physical and chemical transformations of a material when subjected to heating. DSC analysis (Fig. 2) shows one major peak at around $310^{\circ} \mathrm{C}$ attributed to the partial pyrolysis with fragmentation of carbonyl and carboxylic bonds from anhydrous glucose units of cellulose producing carbon and/or carbon monoxide (Santos et al., 2014). The enthalpy of this decomposition was $148 \mathrm{~J} \mathrm{~g}^{-1}$ (Table 2). No crystallization or fusion peaks were observed below the range of thermal degradation as previously observed in others unmodified polysaccharides (Alves, Caridade, Mano, Sousa, \& Reis, 2010). The absence of $T_{g}$ features is frequently detected in cellulose due to its rigid polymer backbone having strong inter- and/or intra-molecular hydrogen bonding and to the rigid amorphous phase because of its heterocyclic units (Lee, Kim, \& Lee, 2000). The addition of chitosan alone to the fabrics does not shown significant difference compared to the control, only a slight increase in the degradation peak temperature and a decrease of the enthalpy due to the lower crystallinity of the coating. However, the addition of the photonic crystal onto the fabric show the appearance of a second endothermic peak at around $430{ }^{\circ} \mathrm{C}$ due to the decomposition of the (P(St-MMA-AA)) as confirmed in the TG thermogram. The position of the endothermic peak of the cotton fabric does not change significantly. However, the enthalpy of the cellulose showed a significant reduction after the coating especially in the photonic crystals deposited in the chitosan-modified surface because of its amorphous structure and lowest crystallinity. In particular, the photonic sample pretreated with chitosan and submitted to crosslinking treatment by glutaraldehyde shows the highest degradation temperature $\left(350{ }^{\circ} \mathrm{C}\right)$ and the lowest enthalpy $\left(30 \mathrm{~J} \mathrm{~g}^{-1}\right)$ suggesting that the cross-linker improves fabric stability and affects the cellulose crystallinity (Park, Choi, \& Oh, 2014).

The most important factors to create durable and uniform structural color coatings on textiles are their washing fastness and reflectance properties. The diffuse reflectance spectra of the unwashed and washed cotton fabrics are shown in Fig. 3 and the color data are shown in Table 3. Before washing (Fig. 3a), the uncoated and chitosan coated black cotton almost absorb across the whole visible range $(650-400 \mathrm{~nm})$ with an increasing reflectance in the red region $(650-700 \mathrm{~nm})$ as expected for this type of dye. The choice of a black dyed fabric as substrate is due to the fact that compared to other base colors the black fabric is able to absorb almost all of incident light, regardless of frequency or angle of incidence. The deposition of the photonic crystal onto the cotton surface increases significantly the surface reflectance (15\%) showing a peak in the region between 500 and $600 \mathrm{~nm}$ in agreement with its predominant orange color. The other configurations display a similar behavior but with a higher reflectance (20\%). The sample coated with chitosan followed by a photonics layer 


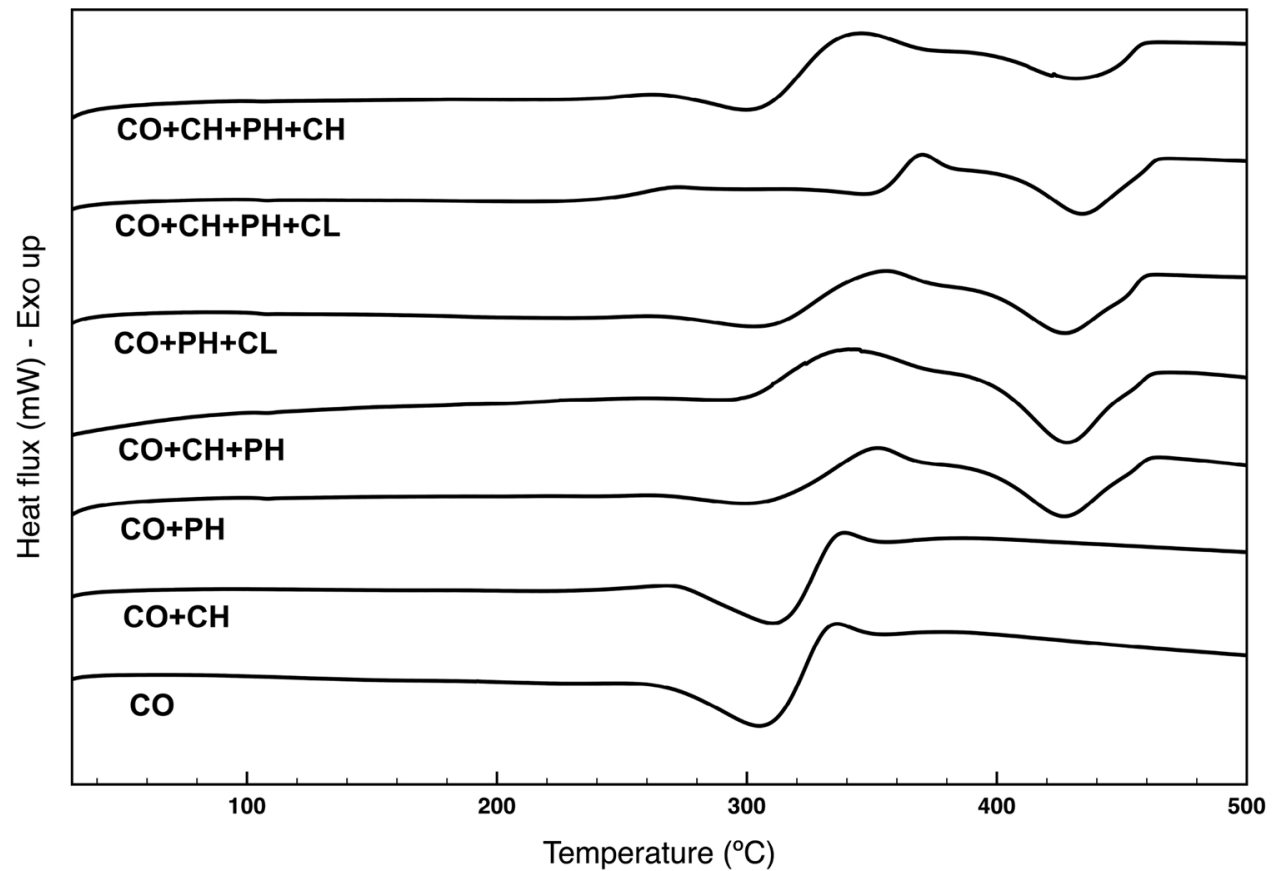

Fig. 2. Differential scanning calorimetry (DSC) thermogram of cotton fabrics with different coating procedures from $20^{\circ} \mathrm{C}$ to $500{ }^{\circ} \mathrm{C}$ performed at a heating rate of $10^{\circ} \mathrm{C} / \mathrm{min}$ under nitrogen atmosphere with a flow rate of $20 \mathrm{~mL} / \mathrm{min}$. CO: Black dyed cotton; $\mathrm{CH}: 1 \%$ Chitosan solution; $\mathrm{pH}$ : $14 \%$ Photonic colloid; CL: $1 \%$ cross-linked chitosan solution. that was stabilized with glutaraldehyde showed the highest reflectance (30\%). A strong reflectance in the photonic band gap indicates a stable colloidal crystals structure onto the black fabric surface. Moreover, the unwanted scattered wavelengths outside the photonic band gap are reduced due to the ability of the black dyed fabric to absorb the transmitted and scattered light outside the photonic band gap enhancing the chroma of structural colors (Liu et al., 2015b). After washing only the sample cross-linked with glutaraldehyde and the sample with an extra layer of chitosan preserve some coating losing in average $5 \%$ of the initial reflectance (Fig. 3b). It is clear that glutaraldehyde acting as a bridging agent between its aldehyde groups and the amino groups of chitosan, the acid groups of photonic nanosphere and the hydroxyl groups of cotton. The observed result of the sample with the P(St-MMAAA) layer imbibed between two layers of chitosan can be explained by the protective action of the outmost layer of chitosan that during washing is removed exposing, without removing, the photonic crystal layer below. The $\mathrm{L}^{*}, \mathrm{a}^{*}, \mathrm{~b}^{*}, \Delta \mathrm{E}^{*}$ and $\mathrm{K} / \mathrm{S} \mathrm{cm}^{-1}$ values listed in Table 3 show in detail the structural color changes. The reference sample used in this work was the unwashed black dyed cotton $(\mathrm{CO}, \mathrm{K} / \mathrm{S}=697.93$, $\left.\mathrm{L}^{*}=0, \mathrm{a}^{*}=0, b^{*}=0\right)$. As can be noticed in Table 3 the $\mathrm{CO}+\mathrm{pH}$ sample after washing is very similar to the control $\left(\Delta \mathrm{E}^{*}=0.7\right.$, $L^{*}=-0.3$ ) due to the very low adhesion of the photonic crystals to the cotton surface. The $\mathrm{CO}+\mathrm{CH}$ sample is also similar to the control sample but due to the high chemical affinity of chitosan with the cellulose structure some lightness is present on the cotton dyed surface even after washing. The sample pre-impregnated with chitosan and with deposited cross-linked nanophotonic crystals (before and after washing) shows the lowest $\mathrm{K} / \mathrm{S}$ and the highest $\mathrm{L}^{*}, \mathrm{a}^{*}, \mathrm{~b}^{*}$, and $\Delta \mathrm{E}^{*}$ values indicating the presence of a high amount of stable photonics absorbed onto the fabric surface. The $\Delta \mathrm{E}^{*}$ values before and after washing indicate the color changing and can be considered as a direct measure of the degree of stability of the photonic crystals onto the fabric surface providing further evidence that cross-linked photonics deposited onto chitosan offer high washing durability.

The size, shape and distribution of the colloidal nanospheres are of great importance for the resulting optical properties of the photonic crystals, thus a SEM analysis was performed to evaluate the synthetized nanospheres and the coating morphologies (Liu et al., 2016). Monodispersed composite latex spheres of P(St-MMA-AA) were successfully synthesized with spherical shape, smooth surface and uniform size distribution by soap-free emulsion polymerization. The P(St-MMA-AA) nanospheres are spherically uniform with an average diameter of $250 \pm 10 \mathrm{~nm}$ (Fig. 4a). The P(St-MMA-AA) nanospheres deposited on black cotton fabrics show a close-packed array with some cracks usually
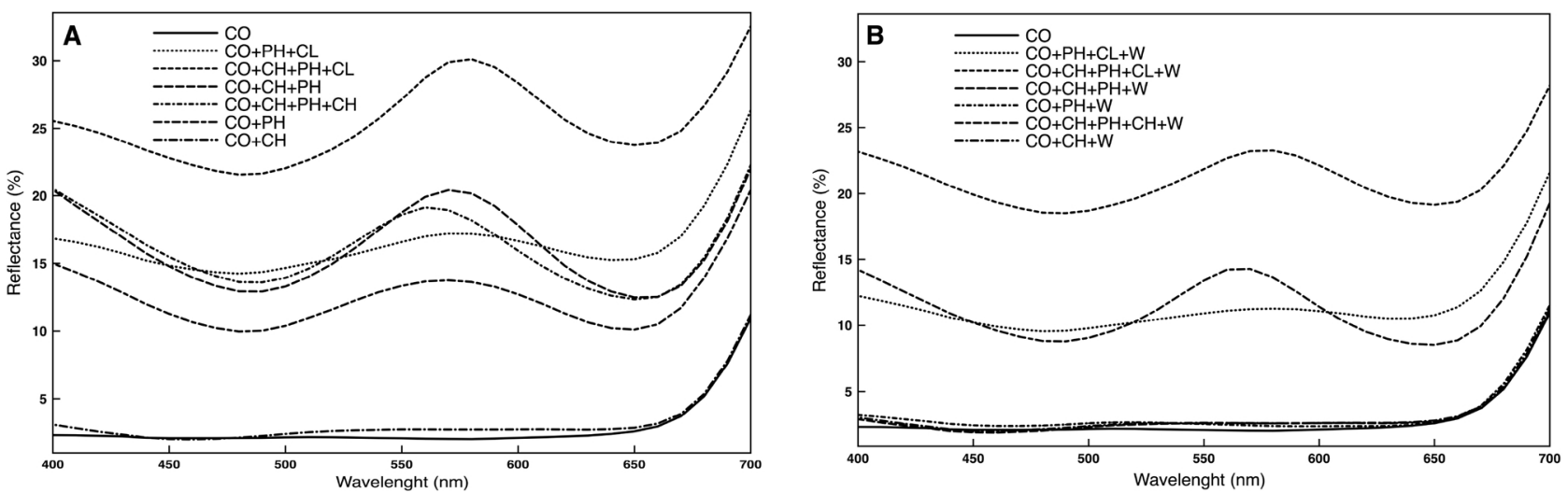

Fig. 3. Diffuse reflectance spectra of unwashed (A) and washed (B) fabric samples. CO: Black dyed cotton; CH: 1\% Chitosan solution; pH : 14\% Photonic colloid; CL: $1 \%$ cross-linked chitosan solution; W: washed. 
Table 3

Color strength (K/S), overall color difference $\left(\Delta \mathrm{E}^{*}\right)$ and shift of the coordinates of the color in the cylindrical color space: lightness $\left(L^{*}\right)$, red-green $\left(a^{*}\right)$, and yellowblue $\left(b^{*}\right)$ of the fabrics $\left(\mathrm{n}=3\right.$; S.D. $<1 \%$ ). Black dyed cotton $\mathrm{K} / \mathrm{S}=697.93, L^{*}=0, a^{*}=0, b^{*}=0$, was used as reference sample for the color difference measures.

\begin{tabular}{|c|c|c|c|c|c|c|c|c|c|c|}
\hline \multirow[t]{2}{*}{ Sample $^{\mathrm{a}}$} & \multicolumn{5}{|c|}{ Unwashed } & \multicolumn{5}{|c|}{ Washed } \\
\hline & $\mathrm{K} / \mathrm{S}$ & $\Delta \mathrm{E}^{*}$ & $L^{*}$ & $a^{*}$ & $b^{*}$ & $\mathrm{~K} / \mathrm{S}$ & $\Delta \mathrm{E}^{*}$ & $L^{*}$ & $a^{*}$ & $b^{*}$ \\
\hline $\mathrm{CO}+\mathrm{CH}$ & 584.5 & 3.4 & 0.3 & 0.4 & 3.3 & 597.2 & 2.6 & -0.1 & 0.4 & 2.6 \\
\hline $\mathrm{CO}+\mathrm{pH}$ & 107.0 & 23.6 & 23.5 & 0.5 & 1.9 & 581.8 & 0.7 & -0.3 & -0.4 & -0.6 \\
\hline $\mathrm{CO}+\mathrm{pH}+\mathrm{CL}$ & 75.4 & 29.0 & 29.0 & 0.9 & 2.0 & 121.5 & 21.0 & 20.9 & 1.6 & 0.6 \\
\hline $\mathrm{CO}+\mathrm{CH}+\mathrm{pH}$ & 75.0 & 30.3 & 30.0 & 0.8 & 3.9 & 616.9 & 3.4 & -0.2 & 0.3 & 3.3 \\
\hline $\mathrm{CO}+\mathrm{CH}+\mathrm{pH}+\mathrm{CL}$ & 39.1 & 40.4 & 40.0 & 2.2 & 5.0 & 51.23 & 35.0 & 34.9 & 1.6 & 1.6 \\
\hline $\mathrm{CO}+\mathrm{CH}+\mathrm{pH}+\mathrm{CH}$ & 75.4 & 29.5 & 29.5 & -1.2 & 1.5 & 104.5 & 23.4 & 23.4 & 1.1 & -0.9 \\
\hline
\end{tabular}

${ }^{\text {a }}$ CO: Black dyed cotton; CH: 1\% Chitosan solution; pH : 14\% Photonic colloid; CL: 1\% cross-linked chitosan solution.

in proximity of the fibers interspace (Fig. 4b). Spheres of equal size in order to occupy the minimum volume can display two different packing arrangement: i) face-centered cubic (FCC) or ii) hexagonal close-packed (HPC). The SEM micrographs confirm a regular close-packed sphere arrangement on cotton fabric but they also show a mixture of FCC and HPC regions with some random packing area. Obtain a specific packing type of P(St-MMA-AA) nanospheres is important because it have a direct effect on the photonic properties. Energetically the FCC structure is preferred over the HCP structure, although the energy difference is small (Zhou, Liu, Wu, Fan, \& Shao, 2014).

The fabrics with deposited PCs on the untreated cotton and chitosan pre-impregnated cotton before and after washing show similar results, however chitosan provide a smoother surface with less cracks on the PCs coating (Fig. 5a and c). After washing, the PCs are significantly reduced on both fabrics exposing the cotton fiber surface (Fig. 5b and d). Nevertheless, chitosan treated fabric display higher washing durability. Chitosan has active hydroxyl and amino groups on its macromolecule chain that strongly interact with the cotton surface producing cationized cotton able to bound the negatively charges PCs (Chattopadhyay, 2001).

The introduction of the cross-linker to the system clearly improves the deposition of the photonic crystal onto the fabric. The untreated and chitosan treated cotton fabric show similar results due to the glutaraldehyde action that promote the formation of an even surface encasing thick layers of photonic structures (Fig. 6a and c). Sometimes thin layers of photonic structures are also present on film surface. It is important to point out that this superficial film does not interfere with the iridescence of the coated fabric. After washing the sample without chitosan cationization step display delamination of the photonic structures exposing in some extent the dyed cotton surface (Fig. 6b). On the contrary, the cationized cross-linked cotton does not show significant changes after washing confirming that the glutaraldehyde action is not limited to the P(St-MMA-AA) nanospheres but it is extended to the chitosan layer providing enhanced stability and washing fastness (Fig. 6d). Glutaraldehyde and chitosan act as a cross-linked matrix filling up the gaps between $\mathrm{P}(\mathrm{St}-\mathrm{MMA}-\mathrm{AA})$ nanospheres in a complex process forming random $\mathrm{N}=\mathrm{CHCH}=\mathrm{C}<$ and $\mathrm{O}=\mathrm{CHCH}=\mathrm{C}<$ bond types (Kildeeva, Perminov, Vladimirov, Novikov, \& Mikhailov, 2009). In this way, the anionic - $\mathrm{COOH}$ groups of the photonic crystal nanospheres by glutaraldehyde action can link to the amine of the chitosan macromolecule chain forming a very stable and resistant coating. The sample without glutaraldehyde but with the additional chitosan surface layer shows a very close packed structure in which the polysaccharide filling the gaps among the P(St-MMA-AA) nanospheres (Fig. 6e). This peculiar configuration display a different opalescence and color appearance due to the new geometry provided by the chitosan surrounding the nanospheres but also due to the change in the lattice structure of the fabric surface induced by the differences in light adsorption between P(St-MMA-AA) and chitosan (Xin-Yuan, 2004). After washing most of the chitosan in removed together with a first layer of nanospheres exposing an untouched second layer of photonic crystals. However, only part of the fist layer is removed maintaining a regular coating of photonic crystal with large gaps among nanospheres that alter the opalescence effect without reducing its intensity. This result suggests that the use of a layer-by-layer approach using chitosan for the construction of effective structural color coatings can avoid the utilization of harmful chemicals such as glutaraldehyde.

Fig. 7 shows the photographs under natural light at different angles of a cross-linked cotton fabric coated with the self-assembled colloidal PCs after a washing cycle. Some gaps exposing the black cotton have appeared however the fabric still maintains a reasonable degree of uniformity and iridescence. This mean that an homogeneous
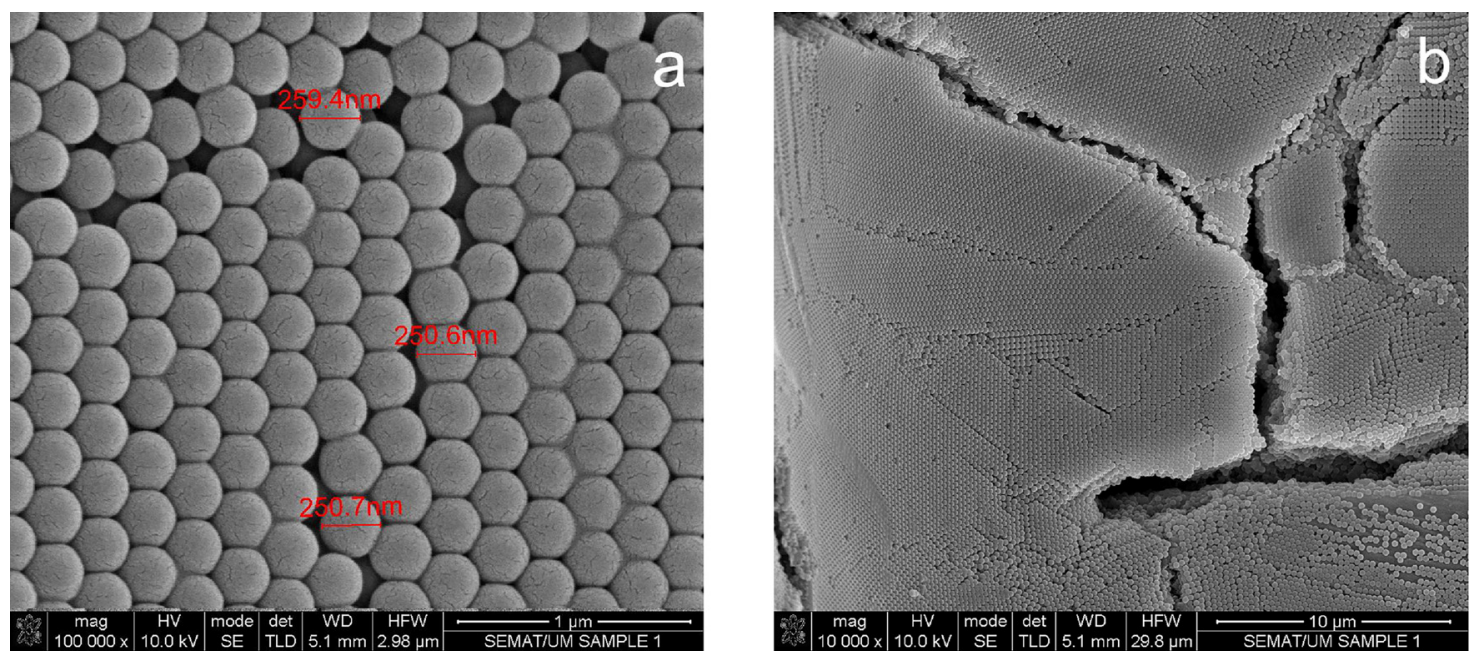

Fig. 4. $\mathrm{P}($ St-MMA-AA) nanospheres size (a) and distribution (b) on black cotton fabric. 

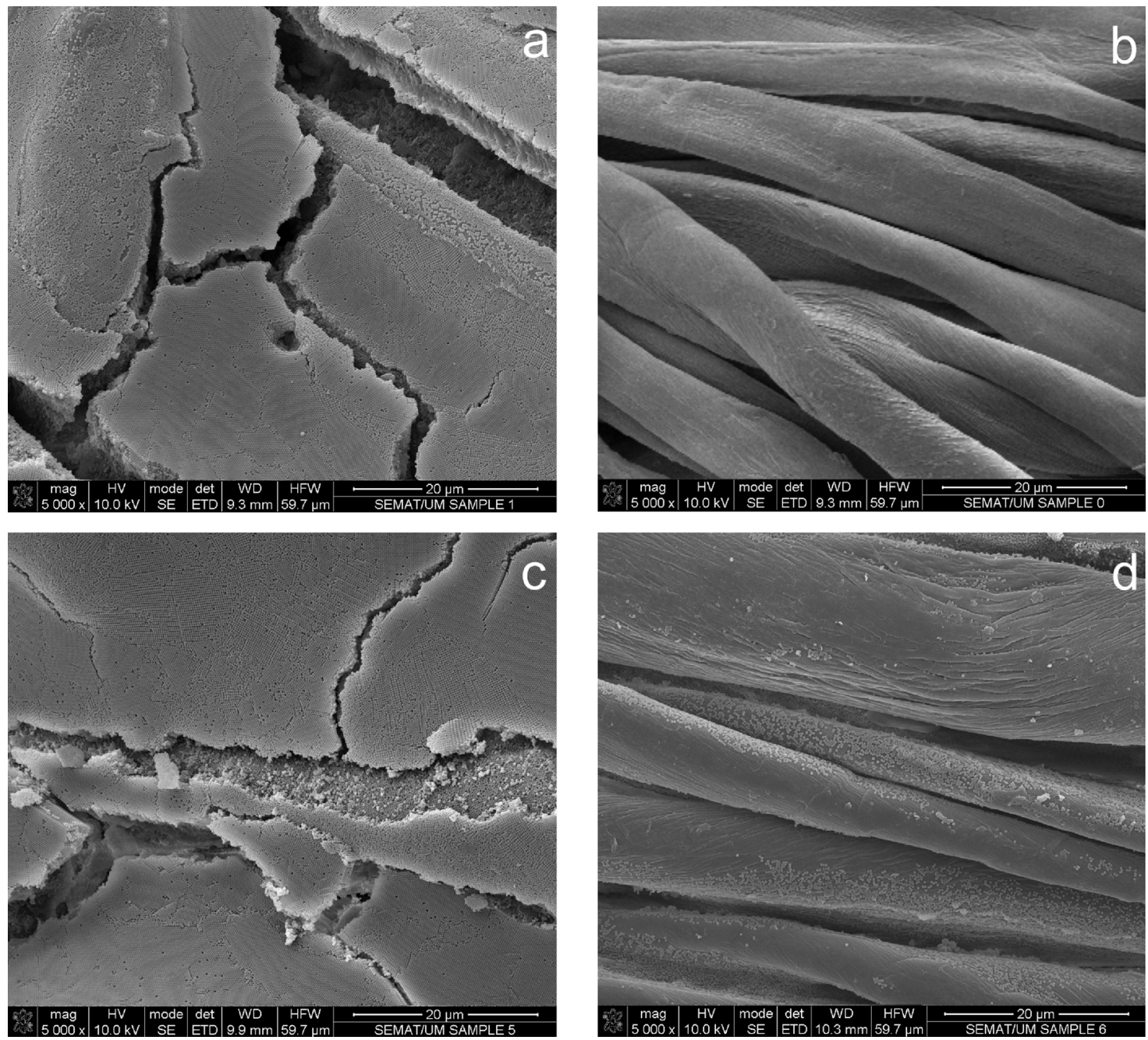

Fig. 5. P(St-MMA-AA) coated onto untreated and chitosan pre-treated cotton before (a, c) and after washing (b, d).

distribution of nanospheres are maintained allowing large domains of crystalline arrays that are necessary for the occurrence of structural colors in the visible region (Zhou et al., 2015). The fabric displays different structural colors at different viewing angles. It is clear that the orientation-dependent Bragg diffraction change to shorter wavelength increasing the viewing angles from $0^{\circ}$ to $90^{\circ}$. The iridescence of structural colors can be also tuned changing the nanospheres size (data not shown). An increase in the PCs sizes result in a red shift of the photonic band gap while a decrease on their size result in a blue shift in the visible spectrum (Liu et al., 2015a). Light fastness test on the fabric shows no significant changes in color compared to a conventional dyed fabric.

The ATR-FTIR analysis (Fig. 8) of the uncoated black cotton control fabric (CO) displays the typical absorption peaks of cellulose structure. The two broad bands of the $\mathrm{OH}$-stretching vibrations arising from hydrogen bonding in cellulose at 3330 and $3270 \mathrm{~cm}^{-1}$ are assigned to intra- and inter-molecular hydrogen bonding of cellulose, respectively (Abidi, Cabrales, \& Haigler, 2014). The intensities of methylene peaks at 2920 and $2850 \mathrm{~cm}^{-1}$ are attributed to $\mathrm{CH}_{2}$ asymmetrical and symmetrical stretching indicating the amount of noncellulsic materials such as proteins, pectin and wax remaining in the fibers after the washing out of the soluble sugars moeites (Souza et al., 2014). The strong peaks at 1150,1100 and $1020 \mathrm{~cm}^{-1}$ are from the vibrations of the $\mathrm{C}-\mathrm{O}-\mathrm{C}$ bond of the glycosidic bridges of the cellulose structure (Algar et al., 2015). The chitosan-coated fabric $(\mathrm{CO}+\mathrm{CH})$ did not show significant differences compared to the control because the characteristic bands of amide I and amide II of the chitosan at 1640 and $1420 \mathrm{~cm}^{-1}$, respectively, are also attributable to the black dye structure (Ibrahim, Osman, \& Mahmoud, 2011). Moreover, the peaks between 990 and $1100 \mathrm{~cm}^{-1}$ attributed to the $\mathrm{C}-\mathrm{O}$ stretching of free and condensed $\mathrm{C}-\mathrm{OH}$ groups are the same of the cotton structure (Goodarzi, Jafari, Khonakdar, Ghalei, \& Mortazavi, 2013). In the photonic crystal coated cotton $(\mathrm{CO}+\mathrm{pH})$ the main bands of cellulose disappeared indicating an effective coating of the fabric surface. The bands at 3027, 2922 and $1541 \mathrm{~cm}^{-1}$ can be assigned to $\mathrm{sp}^{3}$ and $\mathrm{sp}^{2} \mathrm{CH}$ stretching and to the bending of $\mathrm{CH}_{2}$ groups of the nanophotonic crystals, respectively. The peaks in the region from 1400 to $1490 \mathrm{~cm}^{-1}$ belong to the deformation of $\mathrm{CH}$ bonds in the methyl groups of the P(St-MMA-AA) structure (Yap, Que, \& Chia, 1991). The absorption band at $750 \mathrm{~cm}^{-1}$ is attributed to the out-of-plane $\mathrm{C}-\mathrm{H}$ deformation of the monosubstituted or 1,2 disubstituted aromatic rings of the crystals (Costa, Avataneo, Bracco, \& Brunella, 2002). The chitosan-pretreated fabric with deposited photonic crystals $(\mathrm{CO}+\mathrm{CH}+\mathrm{pH})$ and the sample with the additional chitosan layer $(\mathrm{CO}+\mathrm{CH}+\mathrm{pH}+\mathrm{CH})$ show the previously observed peaks of the P(St-MMA-AA) and the bands attributed to the chitosan structure. The peak at $750 \mathrm{~cm}^{-1}$ is more intense result from the aromatic ring outof-plane $\mathrm{C}-\mathrm{H}$ deformation and the in-plane $\mathrm{NH}$ deformation vibration of chitosan (Oliveira, Zille, \& Souto, 2014). The new band around $1590 \mathrm{~cm}^{-1}$ can be assigned to $\mathrm{C}-\mathrm{N}$ stretching vibration and refers to the amide group because of the $\mathrm{NH}_{2}$ bending vibration (Souza et al., 2014). The other new peak observed at $1720 \mathrm{~cm}^{-1}$ is attributed to the $-\mathrm{COO}^{-}$anion of the carbonyl group suggesting the existence of a 

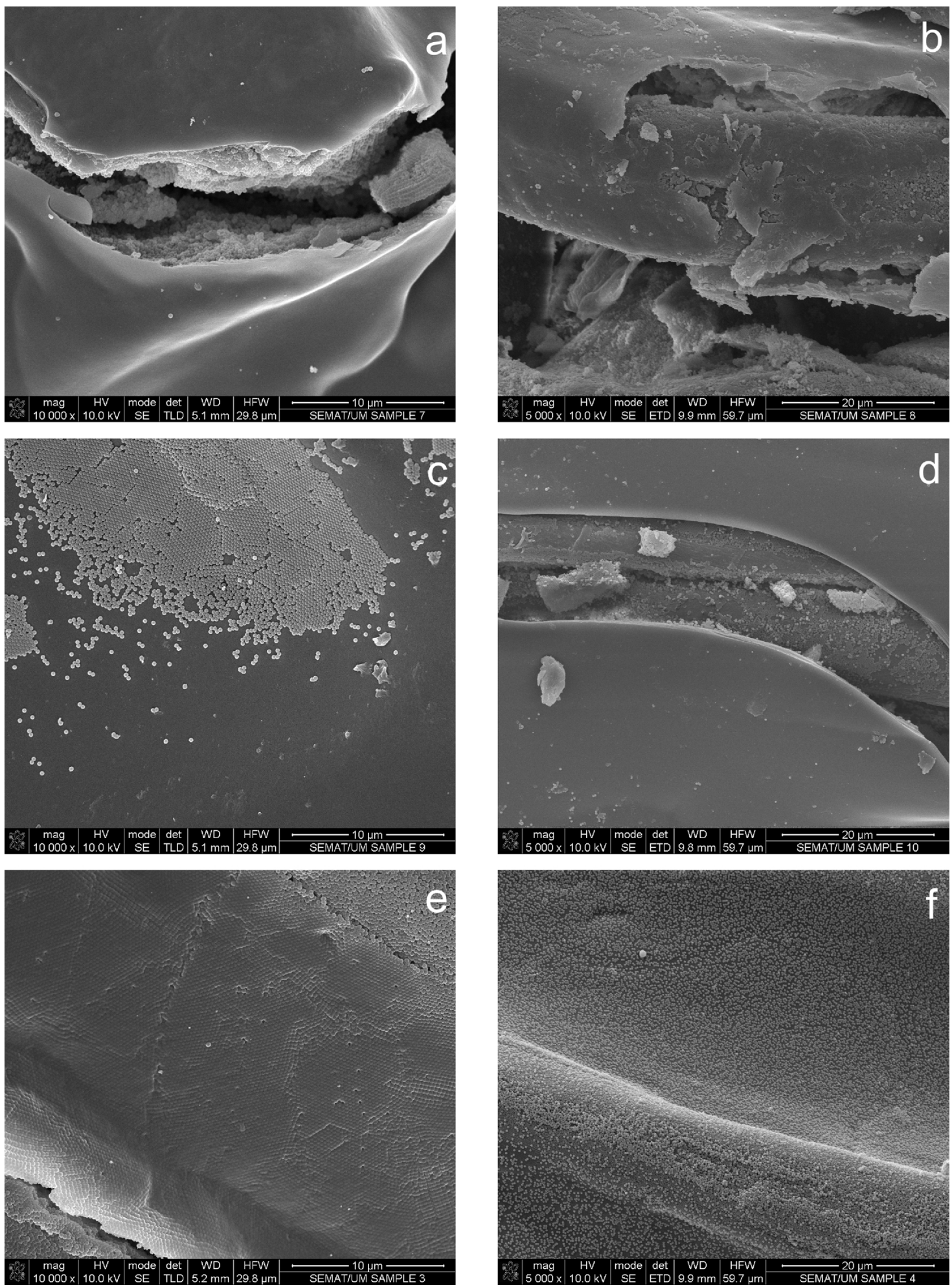

Fig. 6. Cross-linked P(St-MMA-AA) coated onto untreated and chitosan pre-treated cotton before $(\mathrm{a}, \mathrm{c})$ and after washing $(\mathrm{b}, \mathrm{d})$. P(St-MMA-AA) coated onto chitosanpretreated fabric with additional chitosan layer before (e) and after washing (f).

polyelectrolyte complex formed by interaction between the chitosan amino groups and the carboxylic group of P(St-MMA-AA) (Davidenko, Peniche, Diaz, San Roman, \& Sastre, 2007). The addition of the glutaraldehyde to the system $(\mathrm{CO}+\mathrm{pH}+\mathrm{CL}$ and $\mathrm{CO}+\mathrm{CH}+\mathrm{pH}+\mathrm{CL})$ shows the appearance of two new peaks at 1640 and $1550 \mathrm{~cm}^{-1}$ attributable to the carbonyl and ionized carbonyl groups, respectively (Peppas \& Wright, 1996). The presence of this two bands and the disappearance of the peaks of the methyl groups from 1400 to $1490 \mathrm{~cm}^{-1}$ prove the effective crosslinking of the nanophotonic P(StMMA-AA) crystal structures. After washing, the chitosan and the photonic coated fabrics show the characteristic spectrum of the untreated black cotton. The $\mathrm{CO}+\mathrm{CH}+\mathrm{pH}$ sample shows a decrease of the peak at $750 \mathrm{~cm}^{-1}$ assigned to aromatic group of nanospheres. The crosslinked coatings $(\mathrm{CO}+\mathrm{pH}+\mathrm{CL}$ and $\mathrm{CO}+\mathrm{CH}+\mathrm{pH}+\mathrm{CL})$ do not 

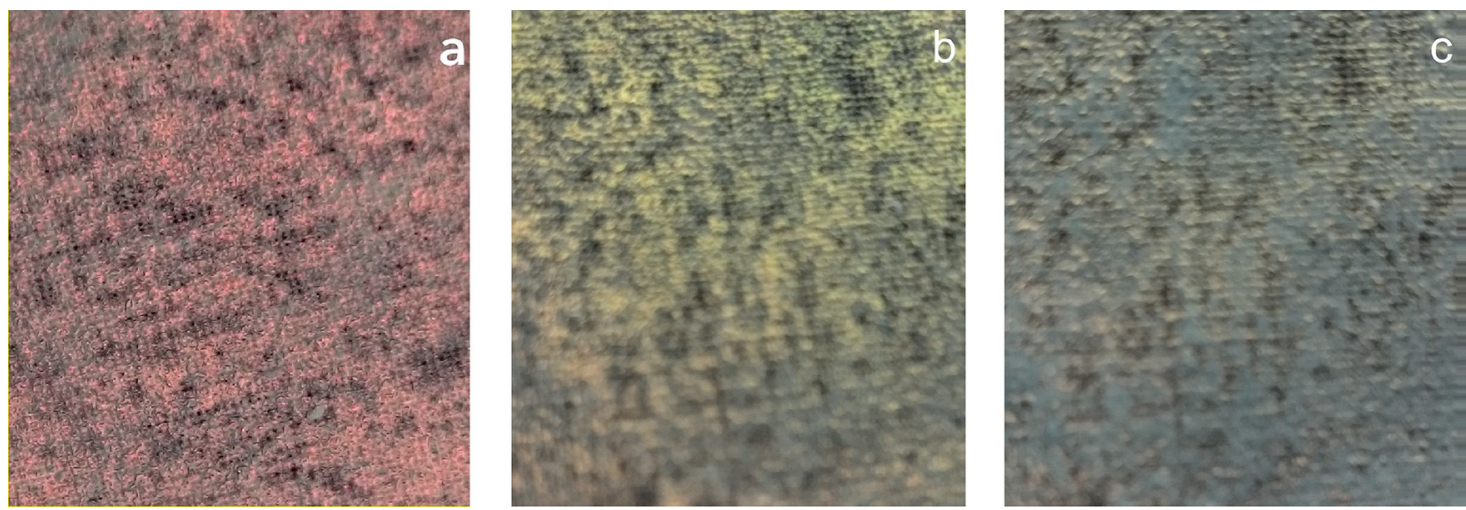

Fig. 7. Photographs of the crosslinked nanophotonics-coated cationized cotton sample at different angles: a) $0^{\circ}$, b) $45^{\circ}$ and c) $90^{\circ}$.
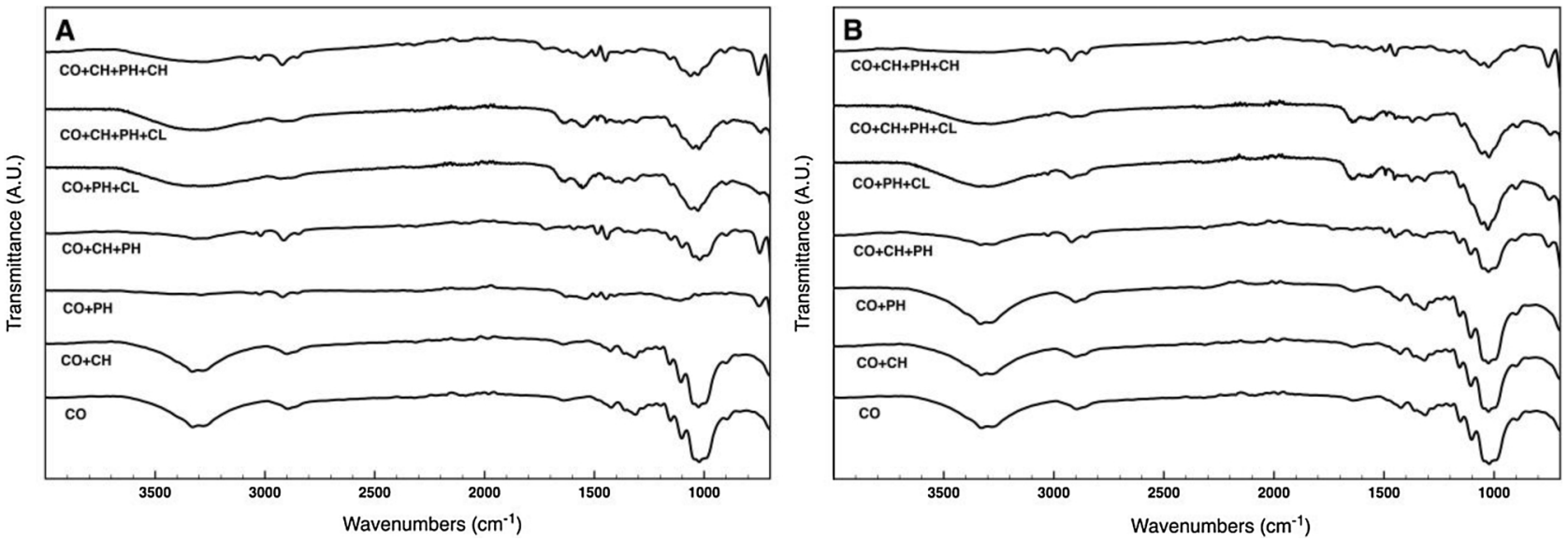

Fig. 8. FTIR-ATR spectra of unwashed (A) and washed (B) fabric samples.

show significant differences as well as the sample with the additional chitosan layer $(\mathrm{CO}+\mathrm{CH}+\mathrm{pH}+\mathrm{CH})$. These results confirm the previous observation by SEM that not only the stabilization ability of glutaraldehyde confer washing durability to the photonic crystal coating but also the additional chitosan layer is able to partially stabilize the nanophotonic P(St-MMA-AA) coating.

\section{Conclusion}

This work demonstrated the structural coloration on woven cotton fabric surface using self-assembled colloidal photonic crystals. The fabric is able to display different iridescence at different viewing angles changing to shorter wavelength as the viewing angle increase from $0^{\circ}$ to $90^{\circ}$. Monodisperse and spherically uniform nanospheres of poly (styrene-methyl methacrylate-acrylic acid) with an average diameter of $250 \pm 10 \mathrm{~nm}$ were successfully synthesized by soap-free emulsion polymerization and efficiently deposited by electrostatic self-assembly technique onto a chitosan-cationized woven cotton fabric. The glutaraldehyde-promoted crosslinking allows durable chemical bonding and higher washing durability between cotton fabric, chitosan and photonic crystals showing the highest degradation temperature $\left(350^{\circ} \mathrm{C}\right)$ and the lowest enthalpy $\left(30 \mathrm{~J} \mathrm{~g}^{-1}\right)$ due to rearrangement of the crystalline structure of the coated cellulose fabric. The color coordinates, K/S and $\Delta \mathrm{E}^{*}$ values show the structural color changes among different coating indicating the elevated amount of stable photonics absorbed onto the cross-linked fabric surface and its high washing durability. The SEM micrographs show coatings formed by a mixture of face-centered cubic and hexagonal close-packed regions with some random packing area. FTIR analysis confirms that not only the stabilization ability of glutaraldehyde confers high washing and light fastness but also the additional chitosan layer is able to partially stabilize the nanophotonic coatings. For the first time, structural coloration using self-assembled poly (styrene-methyl methacrylate-acrylic acid) photonic crystals was successfully developed onto woven cotton fabric using chitosan and/or glutaraldehyde as stabilizing agent. This efficient and cost-efficient technique opens new strategies for the development of dye-free coloration of textiles allowing the production of garments for special applications and innovative design with a good degree of washing and light fastness.

\section{Acknowledgments}

This work is supported by FEDER funding on the COMPETE program and by national funds through Portuguese Foundation for Science and Technology (FCT) within the scope of the project POCI-01-0145FEDER- 007136 and UID/CTM/00264. A. Zille also acknowledge funding from FCT within the scope of the contract IF/00071/2015.

\section{References}

Abidi, N., Cabrales, L., \& Haigler, C. H. (2014). Changes in the cell wall and cellulose content of developing cotton fibers investigated by FTIR spectroscopy. Carbohydrate Polymers, 100, 9-16.

Algar, I., Fernandes, S. C. M., Mondragon, G., Castro, C., Garcia-Astrain, C., Gabilondo, N., ... Eceiza, A. (2015). Pineapple agroindustrial residues for the production of high value bacterial cellulose with different morphologies. Journal of Applied Polymer Science, 132(1), 41237.

Alves, A., Caridade, S. G., Mano, J.o. F., Sousa, R. A., \& Reis, R. L. (2010). Extraction and physico-chemical characterization of a versatile biodegradable polysaccharide obtained from green algae. Carbohydrate Research, 345(15), 2194-2200.

Chattopadhyay, D. P. (2001). Cationization of cotton for low-salt or salt-free dyeing Indian Journal of Fibre and Textile Research, 26(1-2), 108-115.

Choi, S.-W., Xie, J., \& Xia, Y. (2009). Chitosan-based inverse opals: Three-dimensional scaffolds with uniform pore structures for cell culture. Advanced Materials, 21(29), 
2997-3001.

Cong, H., \& Cao, W. (2003). Colloidal crystallization induced by capillary force. Langmuir 19(20), 8177-8181.

Costa, L., Avataneo, M., Bracco, P., \& Brunella, V. (2002). Char formation in polyvinyl polymers I. Polyvinyl acetate. Polymer Degradation and Stability, 77(3), 503-510.

Davidenko, N., Peniche, C., Diaz, J. M., San Roman, J., \& Sastre, R. (2007). Photopolymerisation of acrylic acid and chitosan gels (I). Influence of preparation method on the formation and kinetic behaviour of interpenetrating complexes. Latin American Applied Research, 37(4), 247-253.

Diao, Y. Y., \& Liu, X. Y. (2012). Bring structural color to silk fabrics. Advances in Materials Research, 441, 183-186.

Diao, Y. Y., Liu, X. Y., Toh, G. W., Shi, L., \& Zi, J. (2013). Multiple structural coloring of silk-fibroin photonic crystals and humidity-responsive color sensing. Advanced Functional Materials, 23(43), 5373-5380.

Galisteo-López, J. F., Ibisate, M., Sapienza, R., Froufe-Pérez, L. S., Blanco, Á., \& López, C. (2011). Self-assembled photonic structures. Advanced Materials, 23(1), 30-69.

Goodarzi, V., Jafari, S. H., Khonakdar, H. A., Ghalei, B., \& Mortazavi, M. (2013). Assessment of role of morphology in gas permselectivity of membranes based on polypropylene/ethylene vinyl acetate/clay nanocomposite. Journal of Membrane Science, 445, 76-87.

Hubbe, M. A., Rojas, O. J., \& Lucia, L. A. (2015). Green modification of surface characteristics of cellulosic materials at the molecular or nano scale: A review. BioResources, 10(3), 6095-6206.

Ibrahim, M., Osman, O., \& Mahmoud, A. A. (2011). Spectroscopic analyses of cellulose and chitosan: FTIR and modeling approach. Journal of Computational and Theoretical Nanoscience, 8(1), 117-123.

Jones, M., Burdett, L., Ryan, M., \& Walsh, T. (2016). Efficiency of 2D photonic crystal emitters in thermophotovoltaic systems. PAM Review: Energy Science \& Technology, 3, 153-162.

Kang, Y., Walish, J. J., Gorishnyy, T., \& Thomas, E. L. (2007). Broad-wavelength-range chemically tunable block-copolymer photonic gels. Nature Materials, 6(12), 957-960.

Kildeeva, N. R., Perminov, P. A., Vladimirov, L. V., Novikov, V. V., \& Mikhailov, S. N. (2009). About mechanism of chitosan cross-linking with glutaraldehyde. Russian Journal of Bioorganic Chemistry, 35(3), 360-369.

Kim, S.-H., Lim, J.-M., Lee, S.-K., Heo, C.-J., \& Yang, S.-M. (2010). Biofunctional colloids and their assemblies. Soft Matter, 6(6), 1092-1110.

Kinoshita, S., \& Yoshioka, S. (2005). Structural colors in nature: The role of regularity and irregularity in the structure. ChemPhysChem, 6(8), 1442-1459.

Kumar, C. G., Joo, H.-S., Choi, J.-W., Koo, Y.-M., \& Chang, C.-S. (2004). Purification and characterization of an extracellular polysaccharide from haloalkalophilic Bacillus sp. I-450. Enzyme and Microbial Technology, 34(7), 673-681.

Kuramochi, E., Notomi, M., Kawashima, T., Takahashi, J., Takahashi, C., Tamamura, T., \& Kawakami, S. (2002). A new fabrication technique for photonic crystals: Nanolithography combined with alternating-layer deposition. Optical and Quantum Electronics, 34(1), 53-61.

Lee, S. J., Kim, S. S., \& Lee, Y. M. (2000). Interpenetrating polymer network hydrogels based on poly(ethylene glycol) macromer and chitosan. Carbohydrate Polymers, 41(2), 197-205.

Lee, H. S., Shim, T. S., Hwang, H., Yang, S.-M., \& Kim, S.-H. (2013). Colloidal photonic crystals toward structural color palettes for security materials. Chemistry of Materials, 25(13), 2684-2690.

Liau, L. C.-K., \& Huang, Y.-K. (2008). Effects of influential factors on sedimentation selfassembly processing of photonic band gap crystals by relative humidity-controlled environments. Chemical Engineering and Processing: Process Intensification, 47(9-10), 1578-1584.

Liu, G., Zhou, L., Wu, Y., Wang, C., Fan, Q., \& Shao, J. (2015a). The fabrication of full color P(St-MAA) photonic crystal structure on polyester fabrics by vertical deposition self-assembly. Journal of Applied Polymer Science, 132(13), 41750.

Liu, G., Zhou, L., Wu, Y., Wang, C., Fan, Q., \& Shao, J. (2015b). Optical properties of three-dimensional P(St-MAA) photonic crystals on polyester fabrics. Optical Materials, 42, 72-79.

Liu, M., Xu, W., Bai, J., Chua, C. K., Wei, J., Li, Z., \& Zhou, K. (2016). Investigation of the size effect for photonic crystals. Nanotechnology, 27(40), 405703.

Liu, G., Shao, J., Zhang, Y., Wu, Y., Wang, C., Fan, Q., \& Zhou, L. (2015). Self-assembly behavior of polystyrene/methacrylic acid (P(St-MAA)) colloidal microspheres on polyester fabrics by gravitational sedimentation. Journal of the Textile Institute, 106(12), 1293-1305.

Luduena, L., Fasce, D., Alvarez, V. A., \& Stefani, P. M. (2011). Nanocellulose from rice husk following alkaline treatment to remove silica. Bioresources, 6(2), 1440-1453.

Mocanu, G., Nichifor, M., Mihai, D., \& Oproiu, L. C. (2013). Bioactive cotton fabrics containing chitosan and biologically active substances extracted from plants. Materials Science \& Engineering, C: Materials for Biological Applications, 33(1), 72-77.

Okubo, S. R., Kanawati, A., Richards, M. W., \& Childress, S. (1998). Evaluation of visual and instrument shade matching. Journal of Prosthetic Dentistry, 80(6), 642-648.

Oliveira, F. R., Zille, A., \& Souto, A. P. (2014). Dyeing mechanism and optimization of polyamide 6, 6 functionalized with double barrier discharge (DBD) plasma in air. Applied Surface Science, 293, 177-186.

Osman, E. M., Michael, M. N., \& Gohar, H. (2010). The effect of both UV \ozone and chitosan on natural fabrics. International Journal of Chemistry, 2(2), 28-39.

Ostrander, J. W., Mamedov, A. A., \& Kotov, N. A. (2001). Two modes of linear layer-bylayer growth of nanoparticle-polylectrolyte multilayers and different interactions in the layer-by-layer deposition. Journal of the American Chemical Society, 123(6), 1101-1110.

Park, J. H., Choi, H.-M., \& Oh, K. W. (2014). Simultaneous crosslinking and cationization of cotton cellulose by using dialdehyde and choline chloride: Comparison between the pad-dry-cure and microwave irradiation process. Cellulose, 21(4), 3107-3119.

Peppas, N. A., \& Wright, S. L. (1996). Solute diffusion in poly(vinyl alcohol)/Poly(acrylic acid) interpenetrating networks. Macromolecules, 29(27), 8798-8804.

Pooja, K., \& Chandra, T. (2009). Production and partial characterization of a novel capsular polysaccharide KP-EPS produced by Paenibacillus pabuli strain ATSKP. World Journal of Microbiology and Biotechnology, 25(5), 835-841.

Saito, A. (2016). Material design and structural color inspired by biomimetic approach. Science and Technology of Advanced Materials, 12(6), 064709.

Santos, C., Silva, C. J., Buttel, Z., Guimaraes, R., Pereira, S. B., Tamagnini, P., \& Zille, A. (2014). Preparation and characterization of polysaccharides/PVA blend nanofibrous membranes by electrospinning method. Carbohydrate Polymers, 99, 584-592.

Souza, J. M., Caldas, A. L., Tohidi, S. D., Molina, J., Souto, A. P., Fangueiro, R., \& Zille, A. (2014). Properties and controlled release of chitosan microencapsulated limonene oil. Brazilian Journal of Pharmacognosy, 24(6), 691-698.

Sun, P., \& Williams, J. D. (2012). Photonic paint developed with metallic three-dimensional photonic crystals. Materials, 5(12), 1196-1205.

Turberfield, A. J., Campbell, M., Sharp, D. N., Harrison, M. T., \& Denning, R. G. (2000). Fabrication of photonic crystals for the visible spectrum by holographic lithography. Nature, 404, 53-56.

Uğur, S. S., \& Sarıșı, M. (2011). Electrostatic self-assembly dyeing of cotton fabrics. Coloration Technology, 127(6), 372-375.

Vakhitova, N. A., \& Safonov, S. S. (2003). Effect of chitosan on the efficiency of dyeing textiles with active dyes. Fibre Chemistry, 35(1), 27-28.

Vignolini, S., Rudall, P. J., Rowland, A. V., Reed, A., Moyroud, E., Faden, R. B., ... Steiner, U. (2012). Pointillist structural color in Pollia fruit. Proceedings of the National Academy of Sciences of the United States of America, 109(39), 15712-15715.

Xia, Y., Gates, B., Yin, Y., \& Lu, Y. (2000). Monodispersed colloidal spheres: Old materials with new applications. Advanced Materials, 12(10), 693-713.

Xin-Yuan, S. (2004). New contact lens based on chitosan/gelatin composites. Journal of Bioactive and Compatible Polymers, 19(6), 467-479.

Xu, X., Friedman, G., Humfeld, K. D., Majetich, S. A., \& Asher, S. A. (2002). Synthesis and utilization of monodisperse superparamagnetic colloidal particles for magnetically controllable photonic crystals. Chemistry of Materials, 14(3), 1249-1256.

Yang, Q., Zhu, S., Peng, W., Yin, C., Wang, W., Gu, J., ... Zhang, D. (2013). Bioinspired fabrication of hierarchically structured, $\mathrm{pH}$-tunable photonic crystals with unique transition. ACS Nano, 7(6), 4911-4918.

Yap, M. G. S., Que, Y. T., \& Chia, L. H. L. (1991). Ftir characterization of tropical wood polymer composites. Journal of Applied Polymer Science, 43(11), 2083-2090.

Yavuz, G., Zille, A., Seventekin, N., \& Souto, A. P. (2017). Structural coloration of chitosan-cationized cotton fabric using photonic crystals. IOP Conference Series: Materials Science and Engineering, 254, 102012.

Zhao, Y., Xie, Z., Gu, H., Zhu, C., \& Gu, Z. (2012). Bio-inspired variable structural color materials. Chemical Society Reviews, 41(8), 3297-3317.

Zhao, Y., Shang, L., Cheng, Y., \& Gu, Z. (2014). Spherical colloidal photonic crystals. Accounts of Chemical Research, 47(12), 3632-3642.

Zhou, L., Liu, G., Wu, Y., Fan, Q., \& Shao, J. (2014). The synthesis of core-shell monodisperse P(St-MAA) microspheres and fabrication of photonic crystals Structure with Tunable Colors on polyester fabrics. Fibers and Polymers, 15(6), 1112-1122.

Zhou, L., Wu, Y., Liu, G., Li, Y., Fan, Q., \& Shao, J. (2015). Fabrication of high-quality silica photonic crystals on polyester fabrics by gravitational sedimentation self-assembly. Coloration Technology, 131(6), 413-423.

Zhu, Z., Zhang, J., Wang, C.-F., \& Chen, S. (2017). Construction of hydrogen-bond-assisted crack-free photonic crystal films and their performance on fluorescence enhancement effect. Macromolecular Materials and Engineering, 302(6), 1700013. 